\title{
Research of College Student Management Work
}

\author{
Su Xin ${ }^{1, a^{*}}$, Yang Mao ${ }^{2, b}$ \\ ${ }^{1}$ College of science, Northeast Dianli University, Jilin 132012 \\ ${ }^{2}$ College of electrical engineering, Northeast Dianli University, Jilin 132012 \\ a28366072@qq.com, b yangmao820@163.com
}

Keywords: College student; Management; Connotation; Measures

\begin{abstract}
College education is essentially adult education, thus college management should also be adult management. Colleges are important bases to provide the society with talents, and students' management work will directly affect the cultivation of construction talents of socialist modernization, thus it is worth studying. Students' management work of colleges is different from that of normal junior and senior high schools with its own characteristics. This paper deeply probes the connotation and current situation of college students' management work, and proposes "student-oriented" management concept and corresponding countermeasures such as establishing college teachers and students' faithful information platform as well as enhancing and perfecting the construction of college counselor's teams.
\end{abstract}

\section{Introduction}

College education, an important part in the reform and development of China's higher education, occupies a huge part ofChina's higher education and undertakes the main task of popularizing China's higher education [1]. College education is to cultivate professional talents suitable for all levels and types of schools and bears the responsibility of imparting knowledge and educating people while students' management work is an important guarantee to realize this goal. Therefore, it is a topic that student managers must research to analyze problems in college students' management work of new times following the development of times and propose countermeasures accordingly.

\section{Connotation of College Students' Management}

College students' management involves ideological and political education, routine management, assessment and evaluation of students' work and guidance of students' growth and development [2]. Routine management includes organizing classroom activities, students' financial aid and rewards, daily services and management, mental health monitoring and career guidance, etc. It is of great importance for better realization of college student management to clarify contents involved in college students' management, the specifics of which are as follows:

Guide college students to abide by school and social ethics and establish their suitable life ideal and faith. With dreams, college students enter the ivory tower universities. However, they find it hard to quickly adapt to the relaxing learning environment suddenly, thus fine traditions of the university play a vital role at this moment. Elegant cultural edification, rigorous academic atmosphere and healthy autonomous system will fill students' blankness and solve their confusion, inherit various excellent college traditions among students, and guide college students find their interests and directions as well as establish their own beliefs.

Establish Transparent Legal Management System. College and universities should clarify students' rights and obligations in their regulations and system with rigor and practicability while decentralizing power, fully utilizing students' autonomous system as well as strictly dealing students' relief, awards and punishment. In 
addition, they should also invite relevant personnel to supervise and guarantee students' right to appeal so as to avoid subjective judgment from damaging students' interests.

School Roll Management and Employment Services. Establishing flexible educational system in colleges and universities, credit management, unified management platform across the school reading encourages students to extend learning, development, allowing students to multidisciplinary study, landscape development. Establishment of career guidance in colleges and universities Service Centre, guiding students to do career planning to collect employment information, doing the practice bases construction. Schools should provide time and opportunity for students to learn by themselves, build students' innovation and entrepreneurship base so as to provide a platform for the development of students' interests and promoting college students ' employment.

Life Service. Life service is the most complex work in college students' management and penetrates the entire career of college students. The nanny management is basically the "baton" coming from students' parents, including basic necessities of life and emotional counseling, etc.

Mental Health Education. As more and more of the only-child group become adults, they occupy an increasing proportion in China's college students. In the near future, only-child college students has absolute superiority, teachers' group in colleges and universities not only children occupy absolute advantage. Universities should take appropriate measures to college students' psychological condition monitoring, and in a timely manner to eliminate students' psychological barriers, maintain the mental health of college students.

\section{Current Situation of College Students}

Traditional College Management Model has Low Efficiency without Scientific Management Guidance. Traditional management models are difficult to adapt to the new era college students' characteristics, and its effect will be weakened [3]. In the traditional model, students are generally being the role of managers, teacher leadership as a Manager in a dominant position, such a role of College management there is a light weight management services students passively receive management and arrangement, to take initiative, and creative characteristics of college students' independence and is not consistent. In addition, in the management of college students, lack of secondary guidance of scientific theory, less preventive management, primarily addressing these factors affect the actual effect of University students' management.

Traditional Concept of College Students' Management is Outdated without Innovation. College students' management work has been keeping with the traditional mode while neglecting students' own needs. Traditional management concepts lack "people-oriented" thought and puts excessive emphasis on the role of groups without considering internal control factors of individuals and the development of college students' personality, making the management become rigid and non-flexible. In terms of goal setting, management's objective has been to maintain the stable development of the school, aimed at managing students, manage student, no more long term goals have been set [4]. Student management ultimate objective is to allow students to grow in a stable and orderly environment, which leads should be students than schools in addition, in the event-handling method, traditional moral education thought are punitive, ways, mostly relying on specific rules and regulations for processing. Students often feel the lack of freedom in the school rules, and outward bound students lack the courage to innovation.

Lack of Professional Management Team and Structure is not reasonable. Instructor is a very important part in the management of college students. Now in College, instructor selection and training is not a lack of established rules and regulations management, makes the relatively weak management in colleges and universities, the management of the effect cannot really achieve the effect [5]. Secondly, the college counselor, dedicated instructors is less, some of whom continue to take the opportunity to study through serving as 
short-term counselors, and some of them are teachers in schools. Therefore, the instructor groups prevalent in mobile, lack of operational capacity, and overall quality is not high.

Lack of Learning Theoretical Management Knowledge. Student management work in a foreign country is a highly specialized profession and teachers need to possess knowledge of psychology and pedagogy [6]. While engaged in this occupation are mostly master's, doctoral and other highly educated personnel, lacking in experience and theory research, particularly with respect to administrators, most administrators career are both College teachers, the number is difficult to meet the requirements, let alone reach a high level of professional standards. Due to the smaller number, counselors typically wear several hats, not only to be responsible for the management of students, usually have to complete the task of teaching. Therefore, they are often weak in management without in-depth discussion of theory and research. Home in terms of student management system related to the theory of lacking, most instructors are subject to the influence of traditional empiricism, the guidance of theory in the management of, only by virtue of its experience to complete administrative tasks.

College Students' Own Problems. Contemporary college students are characterized by active, hobbies and more ability to accept new things strong, often at the forefront of the times. But individualism is more prevalent, a strong sense of independence, unwilling to accept others affected by external physical controls and fast-paced life of the community, a large number of university students became impetuous, once the failure will become extremely frustrated, questioning their own capacity, low self-esteem even becomes [7]. With "the post 1990s" in a large part of college students have only one child, somewhat lacking in experience in dealing with setbacks, more prone to psychological gap, psychological problems; on the other hand, the students are from colleges in all over the world, different regions, bringing together people of different cultures together. Because eating habits geographical and cultural differences in family environment, personality aspects of these contacts and exchanges between students often appear contradictory.

\section{Measures to reform and innovate college students' management system}

College students' management system conforms to the historical trend, strengthening the top down reforms, promoting management system suited to China's actual situation in higher education of college students [8]. Main measures are:

Adhere to "Student-Oriented" Management Concept and Establish Modern Democratic Management Concept [9]. Respect the principal position of students, with particular attention to special groups, including poor students, students with psychological disorders and one child, the demand for direct and effective feedback mechanism, solve the difficulties of the special group. Will democratic management philosophy have its roots in the management system of college students, and develop student government management practice. Student managers adhere to the school regulations and the bottom line at the same time, students should be given plenty of rights and freedoms to provide a relaxed environment for the students. Students in the "law" have full discretion, independent organization of campus culture activities, engage in innovative activities.

Establish Academic Credibility Information Platform. Record college students' college career more comprehensively through credit platform and improving school roll management [10]. It can effectively prevent academic misconduct of college teachers to publicize academic credibility information of college teachers and students to the public, and deter college students' profit-orient thought, moral degradation and make them adhere to moral norms of students in college career. Good morality of teachers and students in colleges and universities to promote moral construction in our country has far-reaching significance.

Strengthen and Improve Constructing College Instructor Team. Counselors plays a crucial role for college students' management, but there are many problems in college students' management team, need 
appropriate solutions in the professionalqualities of an administrator in the first place, schools need good pass, should change the traditional teacher is an administrator, no concept of choice. In selection standard, it cannot only depend on its teaching level or literacy, and should more attention to language of expression capacity and organization capacity, some managers need has of professional sex literacy; Second in number, school not should meet current status, except in teachers team in the spread enrollment management personnel, also can to social recruit long time engaged in students management work of career personnel, addition school also can in students groups in the selection a students workers, grow administrator of team, ensure students' management work smoothly.

\section{Summary}

Students are the subject of students' work. They are youth with blood, flesh and their own emotions, so there should be principles, systems and regulations in students' work. Emotions are more needed. Without the investment of emotions, a student work staff cannot fulfill his work.

Students' management work is an extremely complicated systematic project, and we can only do it well through perseverance and according to characteristics of the new era. Colleges and universities should adhere to the student-oriented principle and strengthen innovation of college student management mechanism to cultivate excellent talents for the country.

\section{References}

[1] Huang Meizheng. Problems in Higher Normal Universities' College Management and Countermeasures [J]. Innovation Education, 2015, 11: 120-121.

[2] Jiang Bifeng, Li Rongbiao. On Reform of College Students' Management System [J]. "Management and Technology" the small and medium-sized, 2015, 4: 59-60.

[3] Wu Changwen. Preliminary Exploration of College Students' Management Work [J]. Brand, 2015, 1: 244.

[4] He Xiang. Problems in College Management under New Situation and Strengthening Measures [J]. Journal of Chifeng University (Natural Science Edition) 2014, 30(9): 149-150.

[5] Cheng Li. On How to Do College Management Work Well [J]. Communication of Science \& Technology, 2010, 5: 190-195.

[6] Lin Bin. On Problems in the "Post-1990s" College Students' Management and Strengthening Measures [J]. Journal of Taiyuan Urban Vocational College, 2014, 7: 82-83.

[7] Zhu Ping, Tang Hongjun. On Innovation of Vocational College Students' Management Mechanism under the Background of Connotative Development [J]. Mechanical Vocational Education, 2015, 3: 54-55.

[8] Shu E. On Reform and Development of Students' Management Work [J]. Science and Technology, 2014, 10: 99.

[9] Yu Xiaoting. Study on the three mode type of college student management [J] Modern women, 2014, 10: 12.

[10] Zhang Wei. Study and exploration on college student management mode [J]. Success(education), 2013, 5: $155-156$. 